\title{
Collecting and regenerating populations of the Allium ampeloprasum complex from Greece
}

\author{
Chris Kik *,a , Liesbeth De Groot ${ }^{\mathrm{a}}$, Gerlof Bottema ${ }^{\mathrm{b}}$, Marc Op 't Hof ${ }^{\mathrm{c}}$, Niels De Visser ${ }^{\mathrm{d}}$, Peter \\ Willems ${ }^{\mathrm{e}}$, Toon Van Doormalen ${ }^{\mathrm{f}}$, Stelios Samaras ${ }^{\mathrm{g}}$, Elias Polemis ${ }^{\mathrm{h}}$ and Dimitris \\ Tzanoudakis $^{\mathrm{i}}$ \\ ${ }^{a}$ Centre for Genetic Resources, Wageningen University \& Research, Wageningen, 6700 AA, the Netherlands \\ ${ }^{b}$ Enza Zaden Research and Development B.V, Haling 1/E, 1602 CB, Enkhuizen, the Netherlands \\ ${ }^{c}$ Hazera Seeds B.V, Schansereind 27, 4921 PM, Made, the Netherlands \\ ${ }^{d}$ Rijk Zwaan Zaadteelt en Zaadhandel B.V, Burgemeester Crezéelaan 40, 2678 KX, De Lier, the Netherlands \\ ${ }^{e}$ Bejo Zaden B.V, Trambaan 1A, 1749 CZ, Warmenhuizen, the Netherlands \\ ${ }^{f}$ Nunhems Netherlands B.V, Napoleonsweg 152, 6083 AB, Nunhem, the Netherlands \\ ${ }^{g}$ Hellenic Agricultural Organization-DEMETER, Directorate General of Agricultural Research, Institute of Plant Breeding \\ and Phytogenetic Resources, Thermi-Thessaloniki, 57001, Greece \\ ${ }^{h}$ Laboratory of General and Agricultural Microbiology, Agricultural University of Athens, Athens, 11855, Greece \\ ${ }^{i}$ Section of Plant Biology, Department of Biology, University of Patras, Patras, 26500, Greece
}

\begin{abstract}
Collecting expeditions are of prime importance to acquire genetically unique material, as for many crops and their wild relatives, large gaps are present in collections worldwide. This is also true for the three species of the Allium ampeloprasum complex, native to Greece, which are considered as the crop wild relatives of cultivated leek (Allium porrum). Therefore, a collecting expedition was carried out in Greece in 2009. A total of 62 populations of A. ampeloprasum, 20 populations of $A$. bourgeaui, 19 populations of $A$. commutatum and three mixed species populations were sampled. The sampled populations were mostly small (less than 50 plants), but sometimes large populations (more than 10,000 plants) were encountered, especially for A. commutatum. Two different reproduction systems were observed in A. ampeloprasum, which is probably due to ploidy level differences. The sexual type was predominantly found along cultivated fields, whereas the asexual type occurred in abandoned fields together with Sarcopoterium spinosum (L). Spach and Cistus spp. Regeneration protocols were developed for these species as the phenology of cultivated leek is different from its wild relatives. Regenerating A. ampeloprasum was more difficult compared to the other two species. Ten years after the collecting mission only one-third of the collected material has been regenerated. This is partly due to the characteristics of the material and partly because the Dutch collectors and the Greek competent national authorities on Access and Benefit Sharing were not able to conclude a specific arrangement which also involved the commercial use of the material.
\end{abstract}

Keywords: Collecting expedition, regeneration, mode of reproduction, access and benefit sharing, leek, crop wild relatives

Citation: Kik, C., De Groot, L., Bottema, G., Op 't Hof, M., De Visser, N., Willems, P., Van Doormalen, T., Samaras, S., Polemis, E., Tzanoudakis, D. (2021). Collecting and regenerating populations of the Allium ampeloprasum complex from Greece. Genetic Resources 2 (3), 1-10. doi: 10.46265/genresj.DMAT2233.

(C) Copyright 2021 the Authors.

This is an open access article distributed under the terms of the Creative Commons Attribution License (CC BY 4.0), which permits unrestricted use, distribution, and reproduction in any medium, provided the original author and source are credited.

\section{Introduction}

Crop wild relatives (CWR) are nowadays considered important gene reservoirs for the genetic improvement

*Corresponding author: Chris Kik (chris.kik@wur.nl) of their related crops. However, the occurrence of CWR in genebanks worldwide is often poor and the wild relatives of cultivated leek (Allium porrum L.), namely Allium ampeloprasum L., A. bourgeaui Rech.f. and A. commutatum Guss., are no exception to this (Keller and Kik, 2018). The breeding of new leek cultivars takes 
many years as the crop is a cross-fertilizing (segmental) autotetraploid $(2 n=4 x=32)$. Major challenges in leek breeding are the identification and subsequent introgression of disease (e.g Phytophthora porri) and pest resistances (e.g. Thrips tabaci) as these organisms cause major yield reductions when a crop is infected. Until present no adequate resistances have been found to many diseases and pests in cultivated leek germplasm.

The three CWR of leek form the Allium ampeloprasum complex (von Bothmer, 1970) which can be crossed successfully with their cultivated crop species leek (Kik et al, 1997; Kik, 2002a). Genecological aspects of the three cross-fertilizing wild species have been treated by von Bothmer $(1970,1974)$, taxonomic issues by de Wilde-Duyfjes (1976), Mathew (1996) and Hirschegger et al (2010). Breeding aspects of leek have been treated by de Clercq and Bockstaele (2002).

The geographic distribution of the three CWR species of leek is quite different (Hirschegger et al, 2010). A. bourgeaui is predominantly found on the Greek Aegean islands, but populations of the species have also been recorded from the Aegean coasts of both East continental Greece and West Asia minor. A. commutatum has a broader distribution range compared to $A$. bourgeaui, as it occurs also along the Adriatic coast and on the Mediterranean islands and islets west of the Italian peninsula (Sicily, Sardinia and Corsica). A. ampeloprasum has a very broad distribution range and can be found in the entire Mediterranean region and as far as Afghanistan in the East.

The ecological preferences of the three species differ to a large extent. A. ampeloprasum is a ruderal species which occurs in disturbed places such as cultivated and abandoned fields; population sizes range from small to large. A. bourgeaui is a chasmophyte and can be found on limestone cliffs and inland rocky slopes and occurs mostly in small populations. A. commutatum occurs in coastal habitats and can be found on islets and shores and is able to dominate the area (von Bothmer, 1974).

The first collecting expeditions focusing on the three species of the A. ampeloprasum complex took place between 1964-1969 (von Bothmer, 1970) as part of a larger floristic and biogeographical project (19571969) aimed at studying the effects of genetic and reproductive drift in small populations in the central Aegean archipelago (Runemark, 1969, 1970). In case of the Allium study, a total of 66 A. ampeloprasum, $56 \mathrm{~A}$. bourgeaui and $64 \mathrm{~A}$. commutatum populations were sampled (von Bothmer, 1974). In 1982 Q.P. van der Meer (IVT, Wageningen, the Netherlands) received from R. von Bothmer (University of Lund, Sweden) 21, 16 and 39 populations of $A$. ampeloprasum, $A$. bourgeaui and $A$. commutatum respectively from this expedition. After 20 years only ten, one and 20 populations of $A$. ampeloprasum, $A$. bourgeaui and A. commutatum respectively were still present in this working collection (Kik, 2002b). In the global GENESYS database (https://www.genesys-pgr.org/) no Allium material collected between 1964 and 1969 in Greece is included and only a few populations of $A$. bourgeaui and $A$. commutatum are present in this database. Given the low numbers of leek CWR accessions in public genebanks and considering the near absence of in situ management of the three Allium species, a new collecting expedition was clearly needed.

The aim of the present paper is to report on a collecting expedition in Greece which took place in 2009, describing the ecologies of the three Allium species, recording the geographic locations of the populations sampled, reporting on the challenges in collecting, regeneration and utilization, and providing two newly developed regeneration protocols for the three wild relatives of leek.

\section{Material and Methods}

\section{Germplasm acquisition}

A field collecting form, based on the modified FAO multicrop passport descriptor list (Alercia et al, 2015), was used to document the passport data of the populations sampled (for collecting details: https://www.wur.nl/en /Research-Results/Statutory-research-tasks/Centre-forGenetic-Resources-the-Netherlands-1/Genebank/Specia 1-collections.htm).

All sampled material received a collecting number, in this case TKxxx (i.e. Tzanoudakis Kik followed by a number). Latitude, longitude and altitude were determined via GPS (Garmin, eTrex series Venture HC) with an inaccuracy of 1-5 meters, using WGS84 as map datum and ddd.dddd ${ }^{\circ}$ as position format. Digital pictures were taken of all collecting sites (Kik, 2009).

Considering the peculiarities of the geography of Greece, the organisation of the mission (continental and insular areas to be visited, period and duration of the expedition) was mainly based on the information from the rich Allium collection (mainly herbarium specimens) deposited at the Botanical Museum of the University of Patras (UPA, Patras, Greece) and on the field experience of the Greek participants, especially of the senior author (D.T.) who is an expert on the taxonomy and geographical distribution of the genus Allium in Greece. The collecting mission took place from July 2 to August 21 2009. Collecting took place in the coastal area of the Peloponnese on the mainland and on the islands Karpathos, Crete, Andros, Kythera and Lesbos (Figure 1).

The three Allium species could easily be recognized in the surrounding vegetation because of the height of their flower stalks (ca. $1 \mathrm{~m}$ ). As a rule of thumb, at least three individual plants needed to be seen at a first glance at a specific location to start an area survey. The area explored by foot per population varied from ca. 0.1 to 2 ha.

The inflorescences of all three species were collected in linen bags $(20 \times 35 \mathrm{~cm})$. For each population collected, a label with the collecting number was put inside the bag and a label attached to the rope which tied up a bag. Whenever possible, around 20 inflorescences 


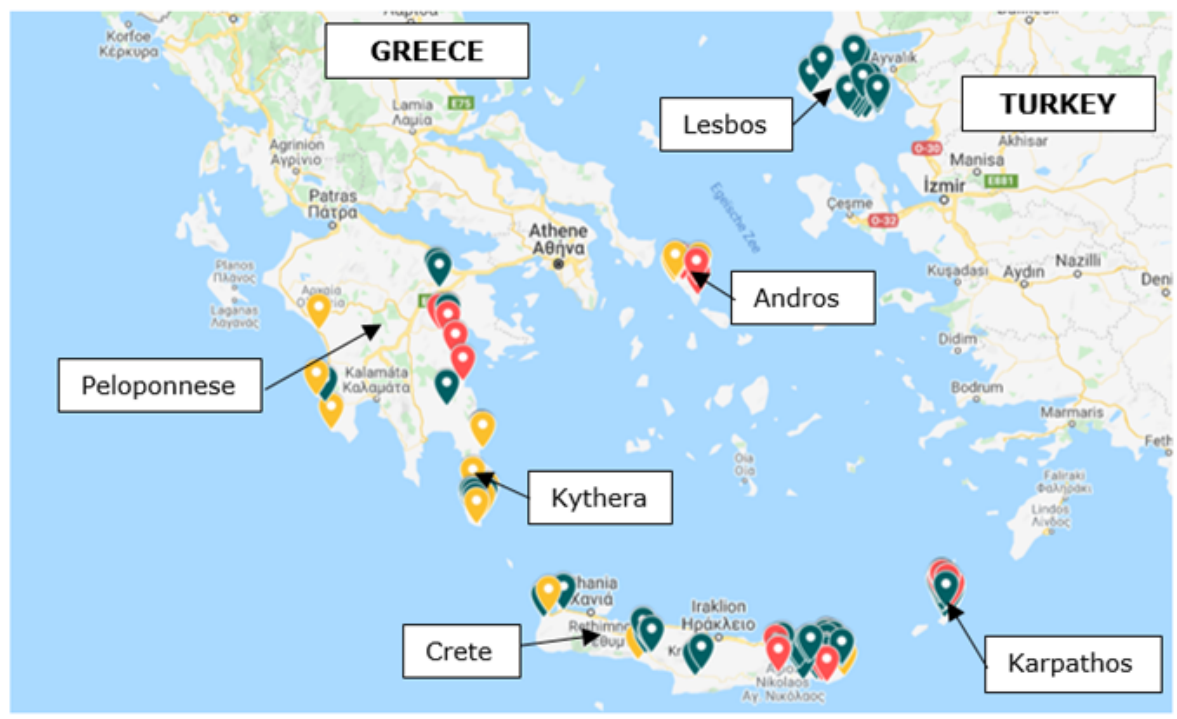

Figure 1. Overview of the collecting sites of the leek CWR collecting mission 2009. The blue, yellow and red dots indicate Allium ampeloprasum, A. commutatum and A. bourgeaui, respectively. For collecting site details: https://www.wur.nl/en/Research-Result s/Statutory-research-tasks/Centre-for-Genetic-Resources-the-Netherlands-1/Genebank/Special-collections.htm

per population were randomly collected and bulked in a linen bag. In almost all cases, the seed was not visible from the outside. Therefore, the quality of the seed was inspected by opening the green fruit capsule (ovary) manually and by checking if the seed was black or white. If fruit capsules in a number of inflorescences contained black (mature) seed, a seed sample was taken. The populations collected at the southeastern coast of Crete always had black seeds as in this part of Greece summer and high temperatures arrive early. Together with the inflorescence, $15-20 \mathrm{~cm}$ of the flower stalk was also collected to provide the maturing seeds with nutrients. If the seeds were still translucent/white, 510 bulblets (small bulbs inside the foliage leaves of the storage bulbs; not to be confused with bulbils which are present in the inflorescence) were collected per plant. In a few cases bulbs were also collected.

Upon arrival at CGN the material was dried outdoors in open plastic cages (day/night temperatures: $+16 / 10^{\circ} \mathrm{C}$; relative humidity: $\sim 75 \%$ ) in linen bags for two weeks. Then the material was transferred for three months to a conditioned storage room with a temperature of $15^{\circ} \mathrm{C}$ and $15 \%$ relative humidity. The seed cleaning also took place in this room. Subsequently, the dried seeds were placed in vacuum-sealed, threelayered aluminum foil bags and stored at $-18^{\circ} \mathrm{C}$, awaiting future regeneration. The bulblets and bulbs sampled during the expedition were planted in mid-November in a conditioned greenhouse.

\section{Ex situ regeneration of the collected seed material}

Protocols had to be developed for the regeneration of Allium ampeloprasum, A. bourgeaui and A. commutatum as the life cycle of cultivated leek is quite different from its wild relatives. Firstly, a protocol (Regeneration protocol I) for regeneration only under the climatic conditions of the Netherlands was developed. However, as regeneration in the Netherlands took three years and plants were lost during the regeneration process, an alternative protocol (Regeneration protocol II) was developed which involved a two stage regeneration process: the first stage took place under the climatic conditions of the Netherlands (Wageningen) and the second step under the climatic conditions of south-east Spain (Cartagena). This protocol took two years and fewer plants were lost.

\section{Regeneration protocol I}

1. Sowing during the last week of August to first week of September of 300 seeds in sowing trays with normal potting soil in a heated glasshouse (day/night temperatures: $+15 / 12^{\circ} \mathrm{C}$ ).

2. After the first seedlings have appeared in the heated glasshouse, the sowing trays should be placed for 3-4 days at $4^{\circ} \mathrm{C}$ to enhance germination; subsequently, the sowing trays are transferred back to the heated glasshouse for 2-3 weeks and the entire procedure of placing the sowing trays at $4^{\circ} \mathrm{C}$ should be repeated if not enough seeds have germinated. This procedure may be repeated 34 times. In the meantime, emerging seedlings are planted in $24 \mathrm{~cm}$ diameter pots ( 3 plants per pot) and placed in a heated greenhouse; care should be taken that plants do not receive too much water.

3. During next May the watering is gradually decreased to a minimum and in the summer months no watering takes place. Watering will start again in September.

4. Every year in August the bulbs are uprooted and bulblets are removed from the main bulb and bulbs replanted again at the end of August or beginning of September. 
5. When the main bulb has a minimum diameter of 4-5 cm flowering is possible. It usually takes about 2.5 years after sowing until the bulb has reached this size.

6. When the plants start flowering in April/May, flowering plants are isolated in cages together with plants from the same population. Regeneration takes place with a minimum of 12 plants per population, using blow flies for pollination. Bulbs that did not produce a flowering stalk can be maintained in the same pot in the greenhouse for the next season.

7. In August, when the seeds have a black colour, the seed stalks are placed upside down in linen bags for drying during 2 weeks, subsequently the seeds are threshed and placed in a paper bag in a drying room $\left(15^{\circ} \mathrm{C}\right.$ and $\left.15 \% \mathrm{RH}\right)$.

\section{Regeneration protocol II}

1. Sowing during the last week of August to first week of September of 300 seeds in sowing trays with normal potting soil in a heated glasshouse (day/night temperatures: $+15 / 12^{\circ} \mathrm{C}$ ).

2. After the first seedlings have appeared in the heated glasshouse, the sowing trays should be placed for 3-4 days at $4^{\circ} \mathrm{C}$ to enhance germination; subsequently, the sowing trays are transferred back to the heated glasshouse for 2-3 weeks and the entire procedure of placing the sowing trays at $4^{\circ} \mathrm{C}$ should be repeated if not enough seeds have germinated. This procedure may be repeated 34 times. In the meantime, emerging seedlings are planted in $24 \mathrm{~cm}$ diameter pots (3 plants per pot) and placed in a heated greenhouse; care should be taken that plants do not receive too much water.

3. During May the watering is gradually decreased to a minimum and in the summer months no watering takes place.

4. The bulbs (diameter ca. $1 \mathrm{~cm}$ ) are harvested in July-August and sent to Cartagena (Spain), where they are planted in the field by the end of August or beginning of September. Individual plants are planted $30 \mathrm{~cm}$ apart from each other (within and between rows) to allow sufficient bulb development.

5. When the main bulb has a minimum diameter of $4-5 \mathrm{~cm}$ flowering is possible. In this environment/these conditions the bulb usually reaches this size 1.5 years after sowing.

6. When the plants start flowering in April/May, flowering plants are isolated by placing cages around plants from the same population. Regeneration takes place with a minimum of 12 plants per population. Blow flies are used for pollination.

7. In August, when the seeds have a black colour, the seed stalks are placed upside down in linen bags for drying during one week, subsequently the seeds are threshed and sent to the Netherlands for further processing.

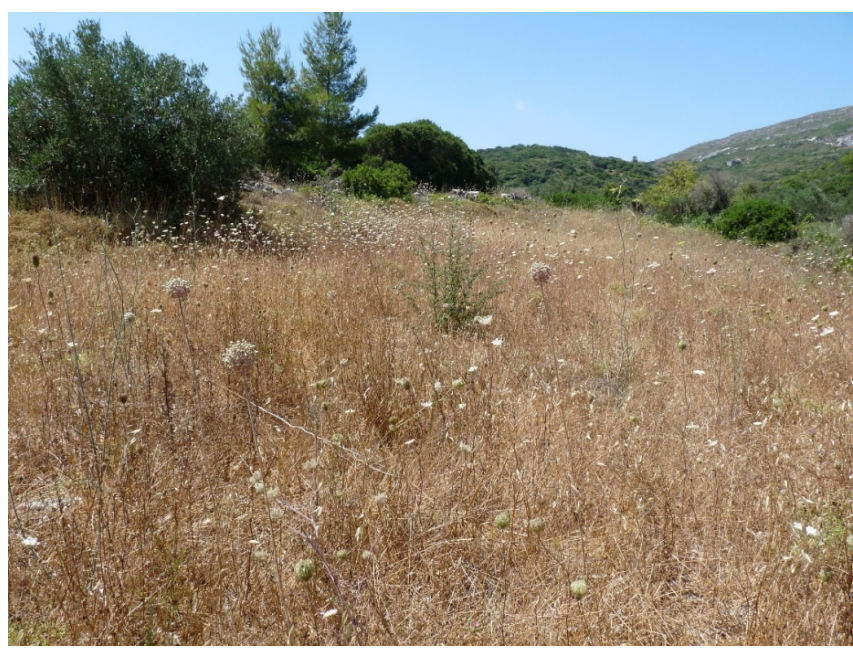

Figure 2. Allium ampeloprasum L. (TK072; Mylopotamos, Kythera) in its natural habitat.

\section{Specific collecting mission arrangements}

An agreement on the basis of which the collecting mission could take place, the so-called Mutually Agreed Terms (MAT), was negotiated between the Greek Ministry of Rural Development and Food, the University of Patras and CGN for the collecting mission. An authorization (prior informed consent; PIC) to collect the three leek CWRs in Greece was issued by the Greek competent national authorities on Access and Benefit Sharing (CNA-ABS) and countersigned by CGN, as a basis for collecting and subsequent distribution of the material. In this arrangement it was agreed that the material collected would be regenerated by CGN and a fair share of each successfully regenerated population will be sent to the Greek genebank. Another agreement was concluded between CGN and a number of breeding companies. In this agreement it was stipulated that breeding companies would co-finance the expedition and help to regenerate the material sampled. Furthermore, an embargo period of five years after the successful regeneration of an accession was negotiated before the material would become available in public databases.

\section{Results}

\section{Ecogeographic description of species of the Allium ampeloprasum complex}

\section{Allium ampeloprasum}

Allium ampeloprasum was mainly found adjacent to cultivated fields or abandoned agricultural fields (Figure 2). Contrary to its name ('ampelos' in Greek means 'vineyard' and 'prason' means 'leek') the species was only observed growing between grapevines on a few occasions. The populations sampled often consisted of 115 plants and were found in altitudes ranging from 5 to 567 meters above sea level (masl).

Two types of $A$. ampeloprasum plants were observed (von Bothmer, 1974): a sexual type (type 
I) with a small inflorescence (ca. $10 \mathrm{~cm}$ in diameter), small bulblets (bulbs in between foliage leaves which embrace the large renewal bulb; $<7 \mathrm{~mm}$ length) and with seeds; and an asexual type (type II) with a large inflorescence (ca. $20 \mathrm{~cm}$ in diameter), larger and more flattened bulblets, and with shrivelled, non- viable seeds (Figure 3).

\section{Allium bourgeaui}

The populations sampled consisted of 1-50 plants collected at altitudes ranging from 2 to 522 masl. According to Mathew (1996) A. bourgeaui comprises three subspecies, subsp. bourgeaui Rech.f., subsp. cycladicum Bothmer and subsp. creticum Bothmer. The three subspecies are distinguished from each other on the basis of the colour and shape of papillae of the perianth. As collecting took place when the flowering period was over and seeds had set, it was not possible to recognize the three subspecies on the basis of these traits. Identification of the three subspecies is nevertheless possible as the three subspecies have a distinct and scarcely overlapping distribution pattern (Mathew, 1996). More precisely, ssp. creticum can only be found in Crete $(\mathrm{N}=5$ populations sampled), ssp. bourgeaui only on the East Aegean islands of Rhodos, Karpathos and Kasos $(\mathrm{N}=6$; Figure 4) and ssp. cycladicum on Cyclades, Ikaria and the eastern part of the Greek mainland $(\mathrm{N}=9)$. The habitats in which these subspecies were found ranged from rocky gorges and steep hillsides to more accessible locations like field borders and hillsides along roads.

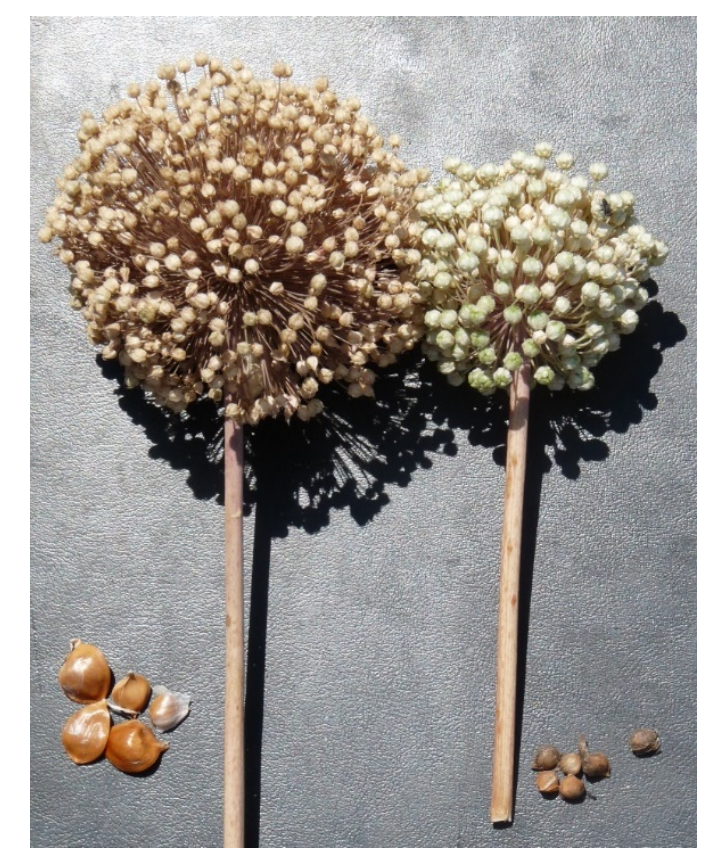

Figure 3. The two Allium ampeloprasum types differ in their mode of reproduction. Inflorescences and bulblets of both types are shown. On the left the asexual type (type II) and on the right the sexual type (type I).

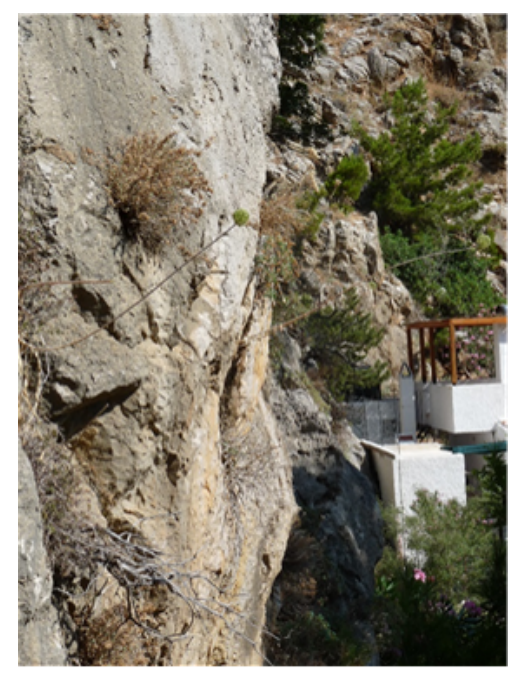

Figure 4. Allium bourgeaui ssp.bourgeaui Rech.f. (TK012; Achata beach, Karpathos) in its natural habitat.

\section{Allium commutatum}

The population size of this species varied considerably between locations: from 1-15 plants (Diakofti, Kythera) to over 100,000 plants (Methoni, Monemvasia, Kythera Chora castles; Figure 5), but it mostly occured in relatively large ( $>50$ plants) populations. When it occured in large populations, it formed mats, where almost no other plant species could be found. These large populations were also found on islets near the coast. During the expedition the species was collected on islets in front of the coast (Andros), but also on coastal shores (Xerokambos, Crete) and close to old castles (e.g. Monemvasia, Peloponnese).

One population was found on a steep rocky inland hill on the western Peloponnese (Lake/Lagoon of Kaiafa; ca. $1 \mathrm{~km}$ from the actual shoreline). However, this can be considered a relict population as in the past, due to the fluctuation of the sea level, the present location of the population was actually a coastal area.

Only a number of islets in front of the Southwestern coast of Andros were visited during this mission due to the relative inaccessibility of these locations. Inhabitants of the islands have knowledge of the presence of Allium species on these islets as these islets are often called 'Prasoudha' or 'Prasonisi' (islet of prason).

\section{Mixed Allium species locations}

On three occasions we observed that next to $A$. commutatum or $A$. bourgeaui also A. ampeloprasum was present (Table 1). The A. commutatum / $A$. ampeloprasum combination was found on a sandy beach plain (Kythera). The A. bourgeaui / A. ampeloprasum combination was found on a clearly disturbed rocky slope along a road (Karpathos) and on a (probably disturbed) rocky slope along a road (Peloponnese). The mixed populations were located at altitudes between 2 and 177 masl. Plants with intermediate morphological characters suggesting hybridization between the two species have not been observed in the localities concerned. 


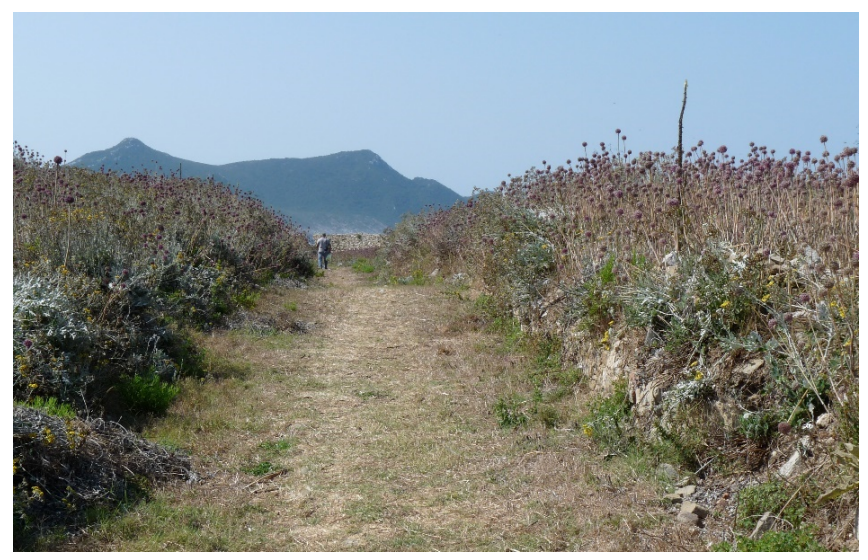

Figure 5. Allium commutatum Guss (TK076; Methoni Castle, Peloponnese) in its natural habitat.

\section{Collecting: number of populations collected}

In total, around 4,000 $\mathrm{km}$ were travelled in Greece by car, boat and plane and 104 populations were collected: 62 single species populations of $A$. ampeloprasum, 20 of $A$. bourgeaui, 19 of $A$. commutatum and three mixed populations, which consisted of two Allium species (Table 1).

\section{Collecting: number of seeds, bulblets and bulbs sampled}

From 65 single species populations enough black mature seed (criterium: $>0.5 \mathrm{~g}=$ ca. 200 seeds) were harvested to be sure that ca. 80 plants per population could be obtained for regeneration. For 36 single species populations this was not the case as the number of mature seeds obtained was below the threshold. For the three mixed populations enough seed could be collected for each population (Figure 6).

A. ampeloprasum clearly differed from the other two species as $42 \%$ (26 out of 62) of the populations did not yield enough seeds, compared to $25 \%$ and $26 \%$ for $A$. bourgeaui and $A$. commutatum respectively. Possible reasons for this could be a) a lower number of plants made up the population; b) immature seeds were collected; and c) presence of plants with different reproduction systems occurring in some populations of A. ampeloprasum. In nine $A$. ampeloprasum populations plants of the two reproduction types (see above) were observed and care was therefore taken to select plants with smaller inflorescences (i.e. sexual plants) and with black matured seed present within green fruit capsules. In three $A$. ampeloprasum and three $A$. bourgeaui populations, only a few plants could be harvested, thus seed sampling could only be taken from fewer than five plants, thus yielding only low seed amounts. From two A. bourgeaui populations vegetative material (bulblets/bulbs) had been collected, which allowed for the multiplication of plants of these populations. When collecting immature seeds, which occurred in four populations of $A$. ampeloprasum, two of $A$. bourgeaui and five of $A$. commutatum, translucent white seeds present within the green fruit capsules were collected, assuming that these seeds could still mature on the stalk. Therefore, inflorescences with ca. $20 \mathrm{~cm}$ flower stalk were collected. However, this precaution proved to be not enough to obtain mature black seeds for these 11 populations. However, as a precautionary measure vegetative material was also sampled for these 11 populations and thus these samples resulted in viable accessions.

\section{Regeneration}

Initially, a protocol (Material and Methods: Regeneration protocol I) was developed for regeneration in the Netherlands. However, the next generation could only be harvested three years after sowing the originally collected seeds. Therefore, a second protocol (Material and

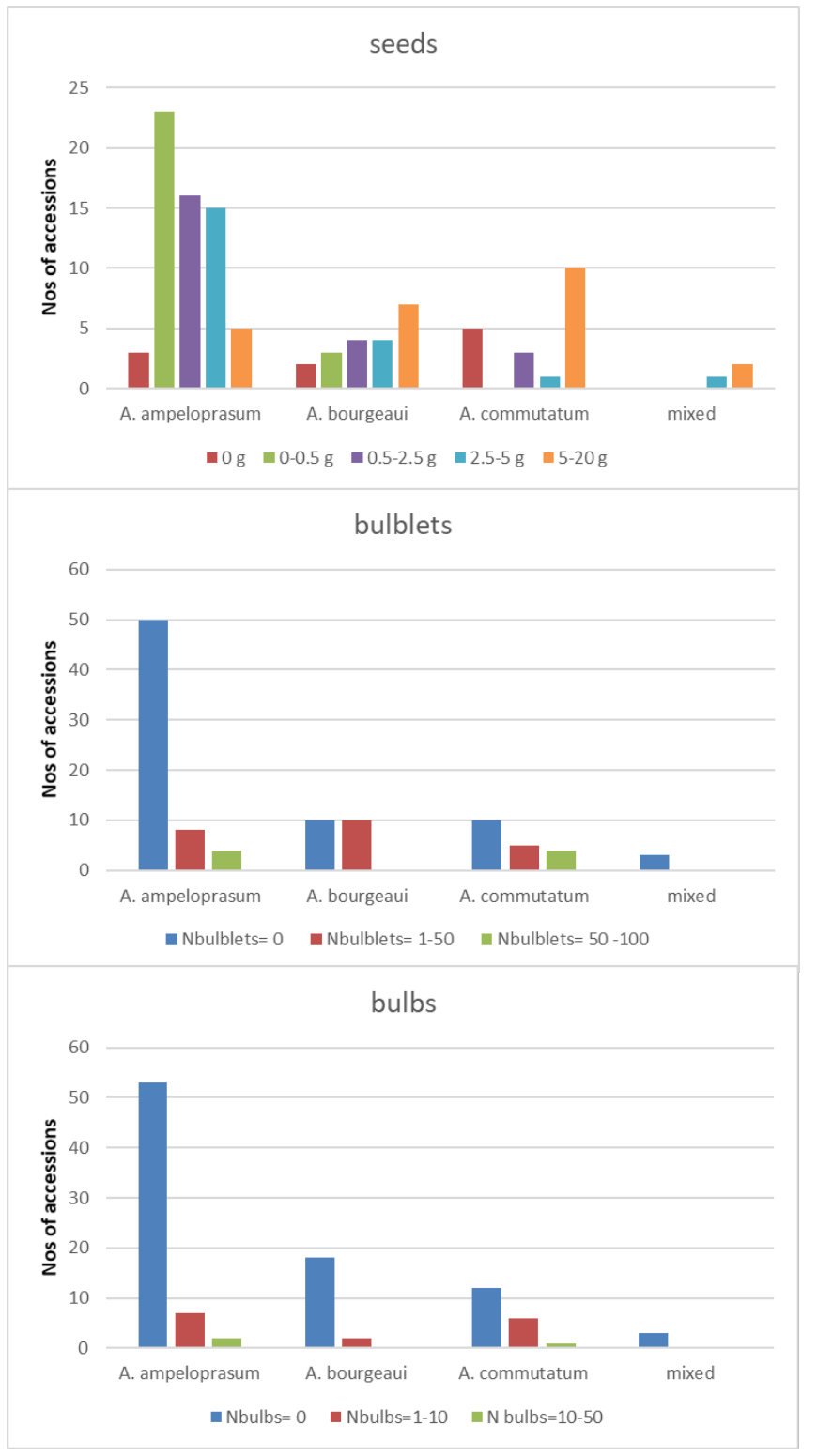

Figure 6. The quantity of seeds and the number of bulblets and bulbs sampled in the various leek CWR populations. When a category on the $\mathrm{X}$-axis is presented as an interval the lower value is excluded from the interval and the higher value is included. 
Table 1. The number of collected leek CWR populations per location visited in Greece; mixed species populations: populations in which two species are present.

\begin{tabular}{lccccc}
\hline Location & A. ampeloprasum & A. bourgeaui & A. commutatum & $\begin{array}{c}\text { Mixed Species Populations } \\
\text { A. ampeloprasum/ } \\
\text { A. commutatum }\end{array}$ & $\begin{array}{c}\text { Ampeloprasum/ } \\
\text { A. bourgeaui }\end{array}$ \\
\hline Karpathos & 9 & & & & 1 \\
Crete & 25 & 5 & 3 & & 17 \\
Andros & 1 & 4 & 6 & 1 & 11 \\
Peleponnese & 4 & 4 & 6 & & 15 \\
Kythera & 10 & & 4 & 1 & 15 \\
Lesbos & 13 & & & & 13 \\
\hline Total & 62 & 20 & 19 & & 2 \\
\hline
\end{tabular}

Methods: Regeneration protocol II) was developed in which the first stages of the regeneration took place the Netherlands and the later stages in Cartagena (Spain). This procedure shortened the production of the next generation of seeds by one year.

As the collecting took place in 2009, the regeneration of the material started in 2010. In 2013 the first eight populations were successfully regenerated and, subsequently these populations were included as accessions in the Dutch genebank (CGN) and placed in the public domain (https://www.wur.nl/en/Research-Results/Sta tutory-research-tasks/Centre-for-Genetic-Resources-theNetherlands-1/Genebank/Special-collections.htm). This was only in 2019, due to an embargo period of five years after the successful regeneration of a population, which had been agreed upon by the breeding companies co-financing the mission and CGN on the material and associated information (Table 2). In the coming years all accessions which were successfully regenerated will be placed in the public domain.

The percentage of populations that have been successfully regenerated until present is 39\% (42/107). The mean germination percentages of the populations regenerated until present are $78 \%, 65 \%$ and $89 \%$ for A. ampeloprasum, A. bourgeaui and A. commutatum, respectively. Eight populations (seven $A$. ampeloprasum and one $A$. bourgeaui) have been donated to the Czech genebank in Olomouc as no seeds could be produced from these populations, but enough bulbs/bulblets were present for vegetatively maintaining these populations. During regeneration, up to now, ten populations of A. ampeloprasum (15\% losses; 10/65), three of $A$. bourgeaui (14\% losses; 3/22) and two of $A$. commutatum (10\% losses; $2 / 20)$ were lost due to no germination or decay of bulbs.

\section{Discussion}

\section{Ecogeography of the species from the Allium ampeloprasum complex}

During the collecting mission more $A$. ampeloprasum populations were collected than $A$. bourgeaui and $A$. commutatum populations. This is probably due to the habitat preferences of the three species: A. ampelopra- sum has a broad ecological amplitude, whereas the other two species have a narrow ecological amplitude. In terms of generalist and specialist species (Fried et al, 2010), A. ampeloprasum can be considered as a generalist and $A$. bourgeaui and $A$. commutatum as specialists. Greece can be considered as an important biodiversity centre for Allium subgenus Allium which is represented in Greece by more than 100 species (Tzanoudakis, 2001; Dimopoulos et al, 2013). In situ management of these species is currently not taking place in Greece, but in case of $A$. bourgeaui and $A$. commutatum this should be considered due to their specific environmental requirements.

The amount of seeds that could be collected from natural populations of the three species varied to a large extent among these species. It was observed that in many populations of $A$. ampeloprasum (42\%) only a few seeds could be harvested. The reasons for this are unclear, but it is possible that this is due the presence of a polyploid series A. ampeloprasum, which is much larger compared to the polyploid series in $A$. commutatum and $A$. bourgeaui, and which might affect seed production (von Bothmer, 1970, 1974). In this context, the presence of plants with different modes of reproduction (sexual and asexual) in $A$. ampeloprasum in cultivated and abandoned fields, especially observed in Kythera, was an interesting phenomenon, probably reflecting different selective forces acting on the species. These forces are probably related to human activities, changes in agricultural methods and land use in general. The sexual type was observed on its own in cultivated fields only, probably due to its generative capacity which allowed the species to co-evolve with the cultivated crops (potatoes, tomatoes, cucumbers, onions). Ploughing in these cultivated fields occurs in early spring and irrigation takes place by running water from springs or by underground well-water. The asexual type was mainly collected from places more dry and remote from villages on larger pieces of land formerly cultivated (ploughed during winter, not irrigated) with crops like cereals (Triticum, Avena, Hordeum) or legumes (Vicia, Lathyrus). After abandoning these fields, species like Sarcopoterium, Cistus and others perennial species dominate. 
Preliminary flow cytometry of a few sexual and asexual individuals showed that the asexual type had higher 2C peaks compared to the sexual type, indicating a higher ploidy level than the tetraploid level (Kik, unpubl. results). Most probably, the sexual type is a (segmental) autotetraploid with $2 \mathrm{n}=4 \mathrm{x}=32$ and not a diploid $(2 \mathrm{n}=2 \mathrm{x}=16$; Guenaoui et al (2013), whereas the asexual type has an increased ploidy level $(2 n>32)$, which might impair sexual reproduction and leads to strong(er) vegetative growth and thus stronger competitive strength.

No cultivation of leek was observed during the collecting mission. However, instead of cultivated leek, wild leek species, i.e. only Allium ampeloprasum and $A$. commutatum, as $A$. bourgeaui is difficult to collect, is used as a condiment in the traditional Greek kitchen (salads, soups, pies etc; Stavridakis (2006). The absence of leek cultivation implies that it is highly likely that no hybridisation and subsequent introgression of genes from the cultivated species into the three wild relatives of leek has taken place. Consequently, no replacement of wild genes has taken place in the three species, which increases their value as a gene reservoir for research and breeding.

\section{Collecting and regenerating the species from the Allium ampeloprasum complex}

\section{Collecting}

The theoretical framework concerning the sampling of populations is well developed for collecting a natural population, using probability-based sampling approaches (Volk et al, 2007). However, in collecting expeditions one deals with more than one population, raising the question of how to balance the number of plants to be collected in populations versus the number of populations to be sampled in a given area to adequately acquire a significant percentage of the genetic variation present in these populations. Until present only a few studies have addressed sampling in more than one population and simulation approaches were used to study the effects of various factors on the collecting of genetic variation present in these populations. In this context Hoban and Scharlbaum (2014) argued that it was not realistic to focus on obtaining $95 \%$ of the variation present in the populations sampled. A more practical approach would be to collect around $75 \%$ of the variation present in these populations. This would require sampling seeds from 20-30 plants per population in case of a diploid species and even less in case of a tetraploid species (Bray, 1983). Therefore, in the case of the three species of the Allium ampeloprasum complex, the aim was to collect seeds from 20-25 plants per population.

Another issue which needs to be taken into account is how to collect in populations where a strong vegetative propagation can be assumed, for example in and around Monemvasia, Methoni and Kythera Chora castles, where large populations ( $>100,000$ plants) of $A$. commutatum are present. To sample these populations appropriately, knowledge about the clonal structure of the populations is essential. However, in case of $A$. commutatum no literature on this issue has been found. The way this problem has been approached in the current collecting expedition was to collect seeds from plants that were meters apart from each other, hoping that they were genetically different from each other.

\section{Regeneration}

Bulk sampling took place within populations instead of sampling seeds from individual plants and keeping their progenies apart. This was done for logistic reasons, as it proved unfeasible to isolate between 10 and 15 biparental crosses per population rather than using one isolation cage for all the plants of a population for each of the 104 collected populations. Bulk sampling and subsequent bulk regeneration per population involves a risk as genetic variation in the subsequent generations could be lost due to random sampling effects (Gale and

Table 2. Overview of the regeneration process of leek CWR. 1) year when material will be publicly available; 2) number of populations; 3) $107=104$ (populations) +3 (mixed species populations that were subdivided during the regeneration process, based on their species identity and thus resulting in three extra populations for regeneration).

\begin{tabular}{|c|c|c|c|c|c|}
\hline & year $^{1}$ & A. ampeloprasum & A. bourgeaui & A. commutatum & Total \\
\hline \multirow{2}{*}{$\begin{array}{l}\text { succesfully regenerated, } \\
\text { already available }\end{array}$} & 2019 & $2^{2}$ & 3 & 3 & 8 \\
\hline & 2020 & 1 & 4 & 6 & 11 \\
\hline \multirow{5}{*}{$\begin{array}{l}\text { succesfully regenerated, } \\
\text { available in }\end{array}$} & 2021 & 2 & 3 & 1 & 6 \\
\hline & 2022 & 0 & 0 & 5 & 5 \\
\hline & 2023 & 2 & 2 & 1 & 5 \\
\hline & 2024 & 3 & 1 & 0 & 4 \\
\hline & 2025 & 1 & 1 & 1 & 3 \\
\hline \multicolumn{2}{|l|}{ to be regenerated } & 37 & 4 & 1 & 42 \\
\hline \multicolumn{2}{|l|}{ lost } & 10 & 3 & 2 & 15 \\
\hline \multicolumn{2}{|l|}{ donated to Czech genebank } & 7 & 1 & 0 & 8 \\
\hline \multicolumn{2}{|c|}{ Total } & 65 & 22 & 20 & $107^{3}$ \\
\hline
\end{tabular}


Lawrence, 1984; Cross and Wallace, 1994). However, the decline in genetic variation in tetraploid species is less compared to diploid species (Bray, 1983). Furthermore, the loss of genetic variation after a number of generations also depends upon the frequency of genes in the collected samples and the ratio of effective population size versus total population size $(\mathrm{Ne} / \mathrm{N})$ in case of cross-fertilizing species, such as the three species of the Allium ampeloprasum complex. However, very important in maintaining the genetic variation in a sample is to keep the number of regenerations as low as possible and to use as many plants as possible per population. Therefore, good storage conditions are essential in this context (van Treuren et al, 2013).

Regenerating the CWR of leek proved to be more difficult than expected, especially as it was thought that the regeneration protocol used for cultivated leek could be applied for its CWR species. However, due to differences in flowering phenologies this was not the case, i.e. the CWRs of leek cannot be regenerated in the same way as leek. Leek is sown in March and grows until autumn in the Netherlands, whereas the CWRs grow during the winter. Leek does not grow in winter, but resumes growth in spring and flowers/sets seed in JuneJuly. The CWRs of leek, on the other hand, are sown in August/September and grow from autumn until spring. At the end of spring the foliage dies back when the bulb has been formed. After the summer (August/September) the bulb sprouts and the growth resumes. When the bulb is large enough, flowering and subsequent seed setting takes place next May/June.

In Regeneration protocol I, the regeneration takes place in the Netherlands and takes three years, whereas in Regeneration protocol II, the regeneration takes place in the Netherlands and in Spain and takes two years. The difference between both protocols is attributable to the better growing conditions in Spain compared to the Netherlands, which favour bulb growth from the end of August to May. A relatively large number of seeds had to be sown as germination percentages varied between $55-83 \%$, depending upon the species. A. ampeloprasum was the species where most losses occurred, so for this species it may be suggested to sow twice as many seeds $(\mathrm{N}=600)$.

\section{Access and Benefit-Sharing issues}

Access and benefit sharing (ABS) is an important aspect in the two international agreements that regulate the exchange of plant genetic resources (PGR), namely the Convention on Biodiversity (CBD) and the International Treaty on Plant Genetic Resources for Food and Agriculture (IT-PGRFA). In this context, national focal points (NFPs) and competent national authorities for ABS (CNA-ABS) have been appointed in the countries that ratified one or both agreements; Greece and the Netherlands ratified both the two agreements. PIC and MAT were concluded before the collecting mission took place, and in the MAT an article was present referring to the Bonn guidelines.
In this context, a problem was encountered which appeared after the collecting mission when the Dutch collectors and the Greek CNA-ABS were not able to conclude a specific arrangement in which it was stipulated that the material collected could also be used for commercial purposes. The consequence was that breeding companies, who were involved in this project, preferred to focus their contributions primarily on material that it could certainly be used in their own breeding programmes. This meant that only a small number of Greek populations could be regenerated annually as the Dutch national genebank CGN did not have sufficient capacity to carry out a large number of regenerations per year, which resulted in a low speed of the regeneration for these three species. Another consequence of not being able to conclude a specific arrangement was that the utilization of the material collected is currently limited to research purposes. Therefore, collecting missions should ensure the appropriateness of the terms and conditions of ABS in all its aspects well before initiating expeditions.

\section{Acknowledgements}

The Dutch Ministry of Agriculture, Nature and Food Quality is gratefully acknowledged for funding this research which was carried out in the framework of the Programme Genetic Resources (WOT-03). In addition, we would like to thank Bejo Zaden B.V., Enza Zaden Research and Development B.V., Nunhems Netherlands B.V., Rijk Zwaan Zaadteelt en Zaadhandel B.V., Hazera Seeds B.V. and Syngenta Seeds B.V. for supporting the collecting and regeneration of the material collected. Furthermore, the manuscript was clearly improved by the contributions of two anonymous reviewers.

\section{Author contributions}

All authors have contributed substantially to the study design, execution, data analysis and interpretation, drafting and revision of the submitted manuscript.

\section{Conflict of interest statement}

The authors declare that they have no conflict of interest, that the work submitted is their own, that copyright has not been breached in seeking its publication, and that the work submitted has not previously been published and is not being considered for publication elsewhere.

\section{References}

Alercia, A., Diulgheroff, S., and Mackay, M. (2015). FAO/Bioversity Multi-Crop Passport Descriptors V.2.1 [MCPD V.2.1]. url: https://hdl.handle.net/10568/ 69166.

Bray, R. A. (1983). Strategies in gene maintenance. In Genetic Resources of Forage Plants, ed. McIvor, J. G. and Bray, R. A., (Melbourne, Australia: CSIRO), 157-168.

Cross, R. J. and Wallace, A. R. (1994). Loss of genetic diversity from heterogeneous self-pollinating 
genebank accessions. Theoretical and Applied Genetics 88(6-7), 885-890. doi: https://doi.org/10.1007/ bf01254001

de Clercq, H. and Bockstaele, E. V. (2002). Leek: advance in agronomy and breeding. In Allium Crop Science: Recent Advances, ed. Rabinowitch, H. D. and Currah, L., (Wallingford, UK: CABI International), 459-491.

de Wilde-Duyfjes, B. E. E. (1976). A revision of the genus Allium L. (Liliaceae) in Africa. Ph.D. thesis, Landbouwhogeschool Wageningen, Wageningen, the Netherlands.

Dimopoulos, P., Raus, T., Bergmeier, E., Constantinidis, T., Iatrou, G., Kokkini, S., Strid, A., and Tzanoudakis, D. (2013). Vascular plants of Greece; an annotated checklist. Volume 31 of Englera. (Berlin, Athens: Botanic Garden and Botanical Museum BerlinDahlem and Hellenic Botanical Society), 1-371.

Fried, G., Petit, S., and Reboud, X. (2010). A specialist-generalist classification of the arable flora and its response to changes in agricultural practices. BMC Ecology 10(1), 20. doi: https://doi.org/10.1186/ 1472-6785-10-20

Gale, J. S. and Lawrence, M. J. (1984). The decay of variability. In Crop Genetic Resources: Conservation and Evaluation, ed. Holden, J. H. W. and Williams, J. T., (UK: Unwin Hyman), 77-101.

Guenaoui, C., Mang, S., Figliuolo, G., and Neffati, M. (2013). Diversity in Allium ampeloprasum: from small and wild to large and cultivated. Genetic Resources and Crop Evolution 60(1), 97-114. doi: https://doi.org/10.1007/s10722-012-9819-5

Hirschegger, P., Jakše, J., Trontelj, P., and Bohanec, B. (2010). Origins of Allium ampeloprasum horticultural groups and a molecular phylogeny of the section Allium (Allium: Alliaceae). Molecular Phylogenetics and Evolution 54(2), 488-497. doi: https://doi.org/ 10.1016/j.ympev.2009.08.030

Hoban, S. and Scharlbaum, S. (2014). Optimal sampling of seeds from plant populations for ex situ conservation of genetic biodiversity, considering realistic population structure. Biol Cons 177, 90-99. doi: https://doi.org/10.1016/j.biocon.2014.06.014

Keller, E. R. J. and Kik, C. (2018). Allium Genetic Resources. In The Allium Genomes, ed. Shigyo, M., Khar, A., and Abdelrahman, M. (Springer, Cham), 2352. Compendium of Plant Genomes.

Kik, C. (2002a). Exploitation of wild relatives for the breeding of cultivated Allium species. In Allium crop science: recent advances, ed. Rabinowitch, $\mathrm{H}$. D. and Currah, L., (Wallingford, UK: CABI International), 81100.

Kik, C. (2002b). The Allium collections at Plant Research International, with special reference to the vegetatively maintained leek (von Bothmer) collection. In Maggioni, L., Keller, J., and Astley, D., in European collections of vegetatively propagated Allium. Report of a workshop, IPGRI, Rome, 50-52.
Kik, C. (2009). Report of a leek (Allium porrum) wild relatives collecting expedition in Greece. volume 2009/15 of CGN report, CGN, Wageningen.

Kik, C., Samoylov, A. M., Verbeek, W. H. J., and van Raamsdonk, L. W. D. (1997). Mitochondrial DNA variation and crossability of leek (Allium porrum) and its wild relatives from the Allium ampeloprasum complex. Theoretical and Applied Genetics 94(3-4), 465-471. doi: https://doi.org/10. $1007 / \mathrm{s} 001220050438$

Mathew, B. (1996). A review of Allium sect. Allium (Richmond, Surrey, UK: Royal Botanic Gardens, Kew), $1-176$.

Runemark, H. (1969). Reproductive drift, a neglected principle in regenerative biology. Bot Notiser 122, 90 128.

Runemark, H. (1970). The Role of small populations for the differentiation in plants. Taxon 19(2), 196-201. doi: https://doi.org/10.2307/1217954

Stavridakis, K. (2006). Wild Edible Plants of Crete (Greece: Privately Published), 1-413.

Tzanoudakis, D. (2001). The genus Allium in Greece: a genus representative of the floristic richness and diversity of the area. In Proceedings 2nd Balkan Bot Congress.

van Treuren, R., de Groot, E. C., and van Hintum, T. J. L. (2013). Preservation of seed viability during 25 years of storage under standard genebank conditions. Genetic Resources and Crop Evolution 60(4), 1407-1421. doi: https://doi.org/10.1007/ s10722-012-9929-0

Volk, G. M., Lockwood, D. R., and Richards, C. M. (2007). Wild plant sampling strategies: the roles of ecology and evolution. In Plant Breeding Reviews, ed. Janick, J. volume 29, 285-313.

von Bothmer, R. (1970). Cytological studies in Allium I. Chromosome numbers and morphology in Allium sect Allium from Greece. Bot Notiser 123, 518-550.

von Bothmer, R. (1974). Studies in the Aegian Flora XXI. Biosystematic studies in the Allium ampeloprasum complex. Opera Botanica 34, 1-104. 